\title{
Expression and significance of RRBPI in esophageal carcinoma
}

This article was published in the following Dove Press journal: Cancer Management and Research

\author{
Liang Wang' \\ Ming Wang ${ }^{2}$ \\ Mingyun Zhang' \\ Xingde $\mathrm{Li}^{\prime}$ \\ Zhongcheng Zhu' \\ Haiyan Wang ${ }^{2}$ \\ 'Department of Endoscopic \\ Professional, Cangzhou Central \\ Hospital, Cangzhou, China; \\ ${ }^{2}$ Department of Radiation Therapy, \\ Cangzhou Central Hospital, Cangzhou, \\ China
}

Objective: This study was to investigate the expression and clinical significance of RRBP1 in esophageal carcinoma.

Materials and methods: RRBP1 expression was detected in 120 esophageal carcinoma and matched adjacent normal tissues, and the relationship of RRBP1 with clinicopathological characteristics and prognosis was analyzed.

Results: RRBP1 was highly expressed in esophageal carcinoma tissues compared with matched adjacent normal tissues $(P<0.05)$. Moreover, RRBP1 expression was associated with $\mathrm{T}$ stage, lymph node metastasis, and TNM stage in esophageal carcinoma $(P<0.05)$. Survival analysis revealed that RRBP1, T stage, lymph node metastasis, and TNM stage were significantly associated with patients' prognosis.

Conclusion: RRBP1 is highly expressed in esophageal carcinoma and can serve as a potential biomarker to predict patients' prognosis.

Keywords: RRBP1, prognosis, esophageal carcinoma, survival analysis

\section{Introduction}

Esophageal carcinoma is one of the most common malignant tumors in China, which accounts for the sixth most common cause of cancer-related death in the world., Surgical resection is the main treatment for esophageal cancer patients; however, the 5 -year survival rate of esophageal cancer patients after surgery is still less than $25 \%{ }^{3,4}$ Currently, the incidence of esophageal carcinoma is still increasing in China. ${ }^{1,5,6}$ The early diagnosis of esophageal carcinoma is a tough challenge. ${ }^{7,8}$ Thus, it would be meaningful to explore novel molecular biomarkers associated with the early diagnosis and prognosis of esophageal cancer.

RRBP1 is an endoplasmic reticulum membrane protein, which plays a critical role in the transportation and secretion of nascent proteins. ${ }^{9}$ Recently, RRBP1 overexpression has been frequently observed in lung cancer, breast cancer, and colorectal cancer. ${ }^{10-12}$ Moreover, RRBP1 correlates with shorter survival and can serve as a valuable prognostic factor in Her-2-positive breast cancer patients. ${ }^{13}$ RRBP1 over-expression contributes to the progression of colorectal cancer and is useful for predicting patients' prognosis. ${ }^{14}$ Thus, this evidence suggests that RRBP1 may be a key oncogene involved in tumor formation and progression. However, the expression and clinical significance of RRBP1 have never been reported in esophageal carcinoma.

In this study, we detected the expression of RRBP1 in 120 cases of esophageal carcinoma and matched adjacent normal tissues, and analyzed the correlation between RRBP1
Correspondence: Liang Wang Department of Endoscopic Professional, Cangzhou Central Hospital, No. 16 Xinhua West Road, Cangzhou 06I00I, China

Email wang23Id@sina.com 
expression and clinicopathological features. Moreover, whether RRBP1 could be a potential prognostic biomarker in patients with esophageal carcinoma was further assessed.

\section{Materials and methods}

\section{Patients and samples}

One hundred and twenty esophageal carcinoma (without chemotherapy and radiotherapy before surgery) specimens were collected from patients presenting to Cangzhou Central Hospital during 2010-2014. Matched adjacent normal tissues were collected $3 \mathrm{~cm}$ from esophageal carcinoma tissue. Patients included 57 males and 63 females with a mean age of 58 years (range, 32-74 years). Clinical pathological characteristics including age, gender, history of smoking, tumor location, T stage, lymph node metastasis, and TNM stage were obtained from hospital records. Follow-up time was from the day of surgery. No patient was lost during follow-up and the follow-up duration ranged from 1 to 65 months (mean, 38.1 months). All the samples were diagnosed as squamous cell carcinoma. The pathological diagnosis was confirmed by two pathologists in Cangzhou Central Hospital.

\section{Quantitative real-time polymerase chain reaction (q-RT-PCR)}

All tissues were frozen in liquid nitrogen. RNA was extracted by RNAisoTM PLUS (Thermo Fisher Scientific, Waltham, MA, USA) and reverse transcribed into cDNA by cDNA Synthesis Kit (TaKaRa Corp, Dalian, China). Quantitative analysis of RRBP1 was performed using 7500 SYBR Green Fast Real-Time PCR System (Thermo Fisher Scientific,). The reaction conditions were $95^{\circ} \mathrm{C}$ for $10 \mathrm{~min}$, followed $95^{\circ}$ for $15 \mathrm{~s}$ for 40 cycles and $60^{\circ} \mathrm{C}$ for $60 \mathrm{~s}$. The primer sequences of RRBP1 were $5^{\prime}$-TGAATCCTCCAAAGACCACA- $3^{\prime}$ and 5'-CTTTCCCTCTCGCGTCTCT-3'. The primer sequences of GAPDH were 5'-CTGAACGGGAAGCTCACTGG-3' and $5^{\prime}$-TGAGGTCCACCACCCTGTTG-3'. The experiments were repeated three times under the same conditions.

\section{Western blot analysis}

All tissues were frozen in liquid nitrogen. Proteins were extracted by protease inhibitors and quantified by the Pierce BCA Protein Assay Kit (Thermo Fisher Scientific). An amount of $50 \mu \mathrm{g}$ per sample was resolved on $5 \%$ sodium dodecyl sulfate polyacrylamide gel electrophoresis and transferred onto polyvinylidene fluoride membranes. After blocking in $5 \%$ fat-free milk at room temperature, membranes were incubated with RRBP1 (Epitomics, Inc., Burlingame, CA, USA) (diluted 1:1000) and GAPDH (Zhongshan Corp, Beijing,
China) (diluted 1:1000) antibodies overnight at $4^{\circ} \mathrm{C}$. Then, membranes were incubated with horseradish peroxidaseconjugated secondary antibodies for $1 \mathrm{~h}$. The signals were measured by enhanced chemiluminescence detection reagents.

\section{Immunohistochemical (IHC) staining}

Sections ( $2 \mu \mathrm{m}$ thick) were deparaffinized with xylene and rehydrated in graded ethanol. Endogenous peroxidase was wiped off with $3 \%$ hydrogen peroxide and antigenicity was repaired by $0.01 \mathrm{~mol} / \mathrm{L}$ sodium citrate buffer (pH 6.0). All sections were incubated with rabbit monoclonal RRBP1 antibody (Epitomics, Inc.) (diluted 1:200) at room temperature for $2 \mathrm{~h}$. After incubation with secondary biotinylated antibody, sections were stained with diaminobenzidine (DAB) and hematoxylin.

The staining of RRBP1 was analyzed by semi-quantitative method. The staining intensity was scored as blank (0), weak (1), moderate (2), and strong (3). The percentage of positive cells was scored as $<5 \%(0), \geq 5 \%-25 \%$ (1), $25 \%-50 \%$ (2), and $>50 \%$ (3). The scores were calculated by multiplying these two values (ranging from 0 to 9 ). These scores ( $\geq 4$ ) were defined as RRBP1 high-expression, and others were defined as RRBP1 low-expression (<4). All IHC scores were assessed by two pathologists independently without the clinical information.

\section{Statistical analysis}

All data were analyzed with SPSS software (version 19.0; IBM Corporation, Armonk, NY, USA). IHC results were analyzed by chi-square test. Survival analysis was performed by the Kaplan-Meier method and log-rank test. Multivariate analysis was assessed by Cox's proportional hazards model. The comparison of two-sample mean was evaluated using independent samples $t$-test. $P$-value of $<0.05$ was defined as statistically significant.

\section{Ethics statement}

This study was approved by the Cangzhou Central Hospital Ethnics Committee. All patients signed informed consent and agreed to the use of their tissue samples in this study.

\section{Results \\ RRBPI is highly expressed in esophageal carcinoma}

First, we detected the expression of RRBP1 in 120 esophageal carcinoma specimens and matched adjacent normal tissues by qRT-PCR and Western blot assays. qRT-PCR results indicated that RRBP1 mRNA level was significantly higher in esophageal carcinoma tissues compared with matched adjacent 
normal tissues (Figure 1A, $P=0.000$ ). Meanwhile, Western blot results revealed that RRBP1 protein was highly expressed in esophageal carcinoma tissues compared with matched adjacent normal tissues (Figure 1B, $P=0.000$ ). These data indicated that RRBP1 was highly expressed in esophageal carcinoma.

\section{RRBPI expression correlates with clinical pathological characteristics in esophageal carcinoma}

Subsequently, we detected the expression of RRBP1 in 120 esophageal carcinoma specimens and matched adjacent normal tissues by IHC. As shown in Figure 2, positive expression of RRBP1 was located in cell cytoplasm and easily observed in esophageal carcinoma tissues, but was hardly detected in normal esophageal tissues. The high-expression rates of RRBP1 in esophageal carcinoma and normal esophageal tissues were $59.2 \%$ and $11.7 \%$, respectively, and the difference was statistically significant (Table $1, P=0.000$ ). Moreover, RRBP1 expression was associated with $\mathrm{T}$ stage, lymph node metastasis, and TNM stage in esophageal carcinoma (Table 2, $P<0.05$ ), but was not associated with age, gender, history of smoking, and tumor location (Table 2, $P>0.05$ ).

\section{High-expression of RRBPI predicts an unfavorable survival rate in esophageal carcinoma patients}

Then, we further analyzed the correlation between RRBP1 expression and patients' survival by Kaplan-Meier method and Cox's proportional hazards model. Kaplan-Meier analysis revealed that the median survival time of patients with RRBP1 high-expression was 43 months, which was significantly shorter compared with those with RRBP1 lowexpression (56 months) (Table 3, Figure 3A, $P=0.006$ ). Moreover, T stage, lymph node metastasis, and TNM stage rather than age, gender, and history of smoking were confirmed to be associated with patients' survival (Table 3, Figure 3B-D, $P<0.05)$. Furthermore, multivariate Cox regression analysis showed RRBP1 high-expression was significantly associated

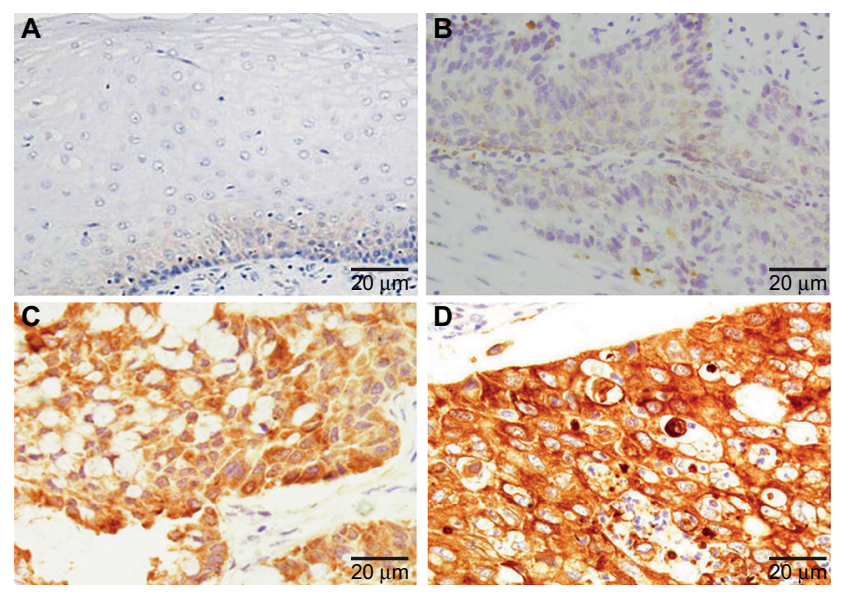

Figure 2 RRBPI expression was detected in esophageal carcinoma and matched adjacent normal tissues by immunohistochemical staining.

Notes: (A) Adjacent normal tissues; (B) weak staining of RRBPI in esophageal carcinoma; (C) moderate staining of RRBPI in esophageal carcinoma; (D) strong staining of RRBPI in esophageal carcinoma.

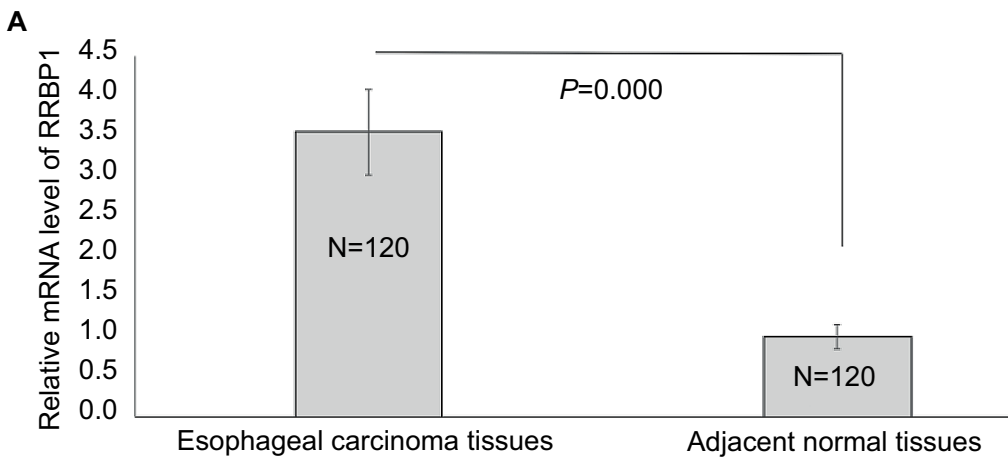

B

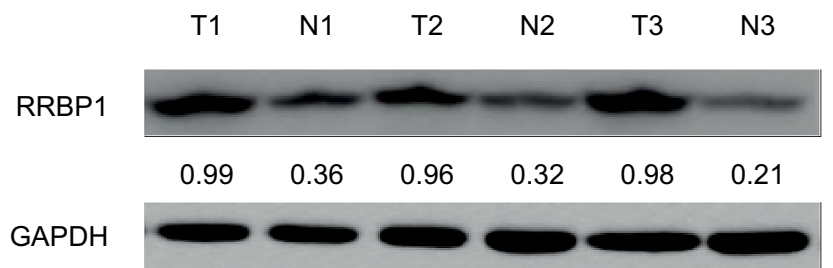

Figure I RRBPI expression.

Notes: The expression of RRBP was detected in esophageal carcinoma and matched adjacent normal tissues by qRT-PCR (A) and Western blot (B). T, esophageal carcinoma tissue; $\mathrm{N}$, matched adjacent normal esophageal tissue. 
Table I RRBPI expression in esophageal carcinoma and normal esophageal tissues by immunohistochemical staining

\begin{tabular}{llll}
\hline Types & N & RRBP I & P-value \\
\cline { 3 - 4 } & & Low-expression (\%) & High-expression (\%) \\
\hline Esophageal carcinoma tissues & 120 & $49(40.8)$ & $71(59.2)$ \\
Normal esophageal tissues & 120 & $106(88.3)$ & 0.000 \\
\hline
\end{tabular}

Table 2 RRBPI expression correlation with clinicopathological characteristics in esophageal carcinoma

\begin{tabular}{|c|c|c|c|c|}
\hline \multirow{2}{*}{$\begin{array}{l}\text { Clinicopathological } \\
\text { characteristics }\end{array}$} & \multirow[t]{2}{*}{$\mathbf{N}$} & \multicolumn{2}{|l|}{ RRBP I } & \multirow[t]{2}{*}{ P-value } \\
\hline & & $\begin{array}{l}\text { Low- } \\
\text { expression }\end{array}$ & $\begin{array}{l}\text { High- } \\
\text { expression }\end{array}$ & \\
\hline \multicolumn{5}{|l|}{ Age (years) } \\
\hline$\leq 58$ & 58 & 27 & 31 & 0.266 \\
\hline$>58$ & 62 & 22 & 40 & \\
\hline \multicolumn{5}{|l|}{ Gender } \\
\hline Male & 57 & 24 & 33 & 0.714 \\
\hline Female & 63 & 25 & 38 & \\
\hline \multicolumn{5}{|l|}{ History of smoking } \\
\hline Negative & 55 & 20 & 35 & 0.853 \\
\hline Positive & 65 & 29 & 36 & \\
\hline \multicolumn{5}{|l|}{ Tumor location } \\
\hline Upper esophagus & 56 & 27 & 29 & 0.14 \\
\hline Middle-lower esophagus & 64 & 22 & 42 & \\
\hline \multicolumn{5}{|c|}{ T stage } \\
\hline TI-T2 & 37 & 30 & 7 & 0.000 \\
\hline T3-T4 & 83 & 19 & 64 & \\
\hline \multicolumn{5}{|l|}{ Lymph node metastasis } \\
\hline Negative & 83 & 42 & 41 & 0.001 \\
\hline Positive & 37 & 7 & 30 & \\
\hline \multicolumn{5}{|l|}{ TNM stages } \\
\hline I-II & 37 & 30 & 7 & 0.000 \\
\hline III-IV & 83 & 19 & 64 & \\
\hline
\end{tabular}

with unfavorable survival rate in esophageal carcinoma. Except for age, gender, history of smoking and tumor location, T stage, lymph node metastasis and TNM stage were also confirmed to be correlated with patients' survival (Table 4, $P<0.05$ ).

\section{Discussion}

RRBP1, an endoplasmic reticulum membrane protein, is mainly located on the endoplasmic reticulum membrane and plays an important role in the transportation and secretion of nascent proteins. ${ }^{911}, 15$ Moreover, RRBP1 is crucial for the terminal differentiation of secretory tissues and the procollagen biosynthesis of secretory tissues. ${ }^{16-19}$ Recently, RRBP1 has been reported to be connected to the regulation of unfolded protein response signaling molecules and the accumulation of perinuclear autophagosomes of cancer cells. ${ }^{10,20,21}$ In addition, RRBP1 was confirmed as an oncogene highly expressed in lung cancer, breast cancer, and colorectal cancer. ${ }^{10-12}$
Table 3 Patient survival: Kaplan-Meier survival analysis

\begin{tabular}{|c|c|c|c|}
\hline Variables & $\mathbf{N}$ & $\begin{array}{l}\text { Survival time } \\
\text { (months, } 95 \% \mathrm{Cl} \text { ) }\end{array}$ & $P$-value \\
\hline \multicolumn{4}{|l|}{ RRBPI } \\
\hline Low-expression & 49 & $56(5 I-60)$ & 0.006 \\
\hline High-expression & 71 & $43(39-48)$ & \\
\hline \multicolumn{4}{|l|}{ Gender } \\
\hline Male & 57 & $5 \mathrm{I}(47-56)$ & 0.323 \\
\hline Female & 63 & $47(42-52)$ & \\
\hline \multicolumn{4}{|l|}{ Age (years) } \\
\hline$\leq 58$ & 58 & $50(45-55)$ & 0.963 \\
\hline$>58$ & 62 & $50(45-54)$ & \\
\hline \multicolumn{4}{|l|}{ History of smoking } \\
\hline Negative & 55 & $49(44-55)$ & 0.845 \\
\hline Positive & 65 & $50(45-54)$ & \\
\hline \multicolumn{4}{|l|}{ Tumor location } \\
\hline Upper esophagus & 56 & $50(45-53)$ & 0.213 \\
\hline Middle-lower esophagus & 64 & $49(45-54)$ & \\
\hline \multicolumn{4}{|l|}{ T stage } \\
\hline $\mathrm{TI}-\mathrm{T} 2$ & 37 & $58(53-62)$ & 0.001 \\
\hline T3-T4 & 83 & $43(39-48)$ & \\
\hline \multicolumn{4}{|l|}{ Lymph node metastasis } \\
\hline Negative & 83 & $55(5 I-59)$ & 0.000 \\
\hline Positive & 37 & $36(3 I-4 I)$ & \\
\hline \multicolumn{4}{|l|}{ TNM stages } \\
\hline I-II & 37 & $58(53-62)$ & 0.033 \\
\hline III-IV & 83 & $43(39-46)$ & \\
\hline
\end{tabular}

RRBP1 over-expression predicts unfavorable survival rates in colorectal cancer patients. ${ }^{14}$ However, the expression and clinical significance of RRBP1 have never been reported in esophageal carcinoma.

In this study, in order to investigate the clinical significance of RRBP1 in esophageal carcinoma, we detected the expression of RRBP1 in 120 cases of esophageal carcinoma and matched adjacent normal tissues by qRT-PCR, Western blot, and IHC assays. qRT-PCR and Western blot results both showed that RRBP1 was highly expressed in esophageal carcinoma tissues compared to matched adjacent normal tissues, suggesting that RRBP1 high-expression might contribute to the occurrence of esophageal carcinoma. Meanwhile, IHC results showed that RRBP1 high-expression was observed in $59.2 \%$ esophageal carcinoma, but only in $11.7 \%$ matched adjacent normal tissues. Thus, IHC results were consistent 
A

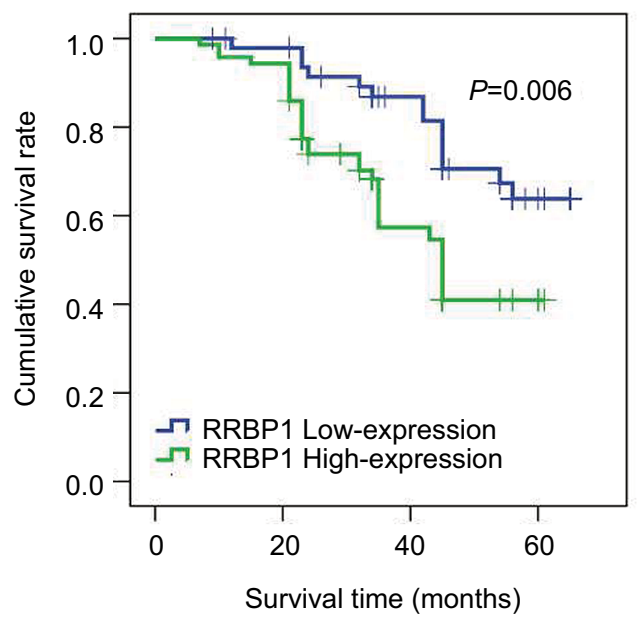

C

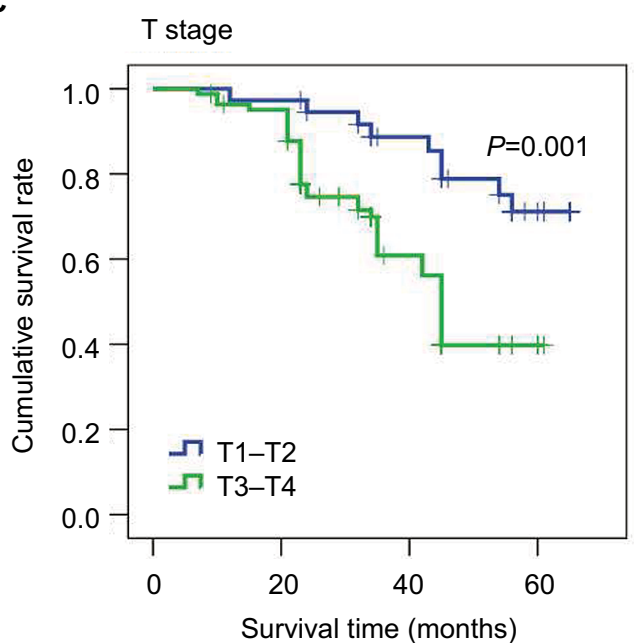

B

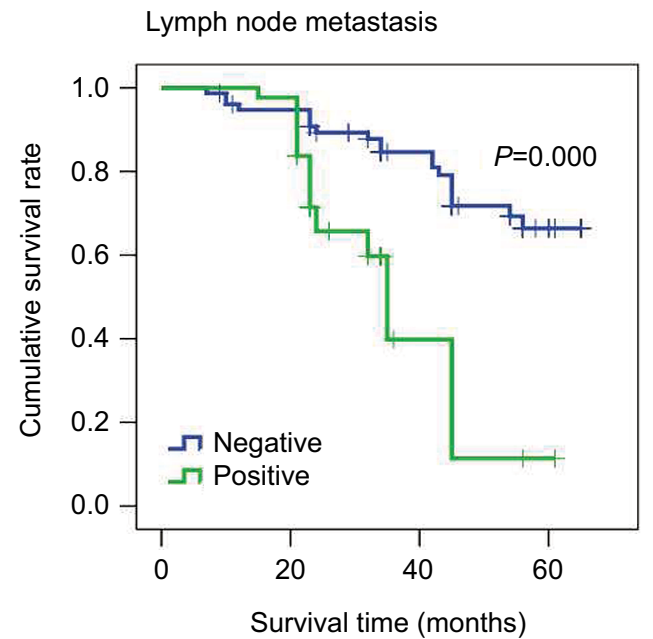

D

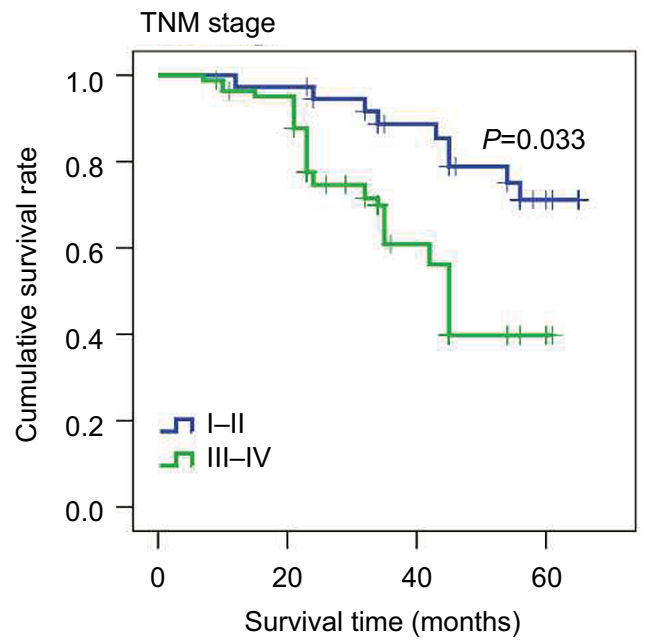

Figure 3 Kaplan-Meier survival analysis.

Notes: Results indicated that RRBPI expression (A), lymph node metastasis (B), T stage (C), and TNM (D) stage were associated with patients' prognosis.

Table 4 Patients' survival evaluation by multivariate Cox regression analysis

\begin{tabular}{|c|c|c|c|}
\hline Variables & $\begin{array}{l}\text { Hazard } \\
\text { ratio }\end{array}$ & $95 \% \mathrm{Cl}$ & $P$-value \\
\hline $\begin{array}{l}\text { RRBPI (high-expression vs low- } \\
\text { expression) }\end{array}$ & $2.44 I$ & $1.267-4.702$ & 0.008 \\
\hline Gender (male vs female) & 1.329 & $0.736-2.400$ & 0.346 \\
\hline Age ( $\leq 58$ vs $>58$ years $)$ & 0.994 & $0.516-1.916$ & 0.987 \\
\hline $\begin{array}{l}\text { History of smoking (positive vs } \\
\text { negative) }\end{array}$ & 0.963 & $0.498-1.862$ & 0.912 \\
\hline $\begin{array}{l}\text { Tumor location (upper vs middle- } \\
\text { lower) }\end{array}$ & 0.929 & $0.538-1.629$ & 0.921 \\
\hline T stage (T3-T4 vs TI-T2) & 3.054 & $1.453-6.42 \mid$ & 0.003 \\
\hline $\begin{array}{l}\text { Lymph node metastasis (positive } \\
\text { vs negative) }\end{array}$ & 4.024 & $2.180-7.424$ & 0.000 \\
\hline TNM stage (III-IV vs I-II) & 3.054 & $1.452-6.42 \mid$ & 0.003 \\
\hline
\end{tabular}

with qRT-PCR and Western blot results, which further supported that RRBP1 high-expression was correlated with the occurrence of esophageal carcinoma. In addition, our data revealed that RRBP1 expression was associated with T stage, lymph node metastasis, and TNM stage in esophageal carcinoma, which suggested that RRBP1 expression might be connected to the progression of esophageal carcinoma. Survival analysis showed that patients with RRBP1 highexpression presented shorter survival rates compared with those with RRBP1 low-expression, indicating that RRBP1 might serve as a prognostic biomarker in esophageal carcinoma. It is well-known that $\mathrm{T}$ stage, lymph node metastasis, and TNM stage are key factors associated with the progression of esophageal carcinoma and patients' survival. ${ }^{22-28}$ In the present study, our data also indicated that $\mathrm{T}$ stage, lymph node metastasis, and TNM stage were independent prognostic factors in esophageal carcinoma. Thus, our data suggested that RRBP1 high-expression might contribute to the progression of esophageal carcinoma, which results in a poorer prognosis. In addition, Liang et al reported that RRBP1 was a valuable prognostic factor in Her-2-positive breast cancer patients. ${ }^{13}$ 
Pan et al reported that RRBP1 promoted the progression of colorectal cancer and predicted prognosis. ${ }^{14}$

\section{Conclusion}

This paper is the first to report that RRBP1 is an oncogene highly expressed in esophageal carcinoma. Additionally, our data indicate that RRBP1 may be connected with the occurrence and progression of esophageal carcinoma, and serve as an independent prognostic factor to predict patients' prognosis. Of course, further investigations are needed to validate our findings.

\section{Acknowledgment}

Thanks to all patients who agreed to participate in this study.

\section{Author contributions}

All authors contributed toward data analysis, drafting and revising the paper and agree to be accountable for all aspects of the work.

\section{Disclosure}

The authors report no conflicts of interest in this work.

\section{References}

1. Han T, Shu T, Dong S, et al. Chemokine-like factor-like MARVEL transmembrane domain-containing 3 expression is associated with a favorable prognosis in esophageal squamous cell carcinoma. Oncol Lett. 2017;13(5):2982-2988.

2. Jemal A, Bray F, Center MM, Ferlay J, Ward E, Forman D. Global cancer statistics. CA Cancer J Clin. 2011;61(2):69-90.

3. Hu JM, Liu K, Liu JH, et al. CD163 as a marker of M2 macrophage, contribute to predict aggressiveness and prognosis of Kazakh esophageal squamous cell carcinoma. Oncotarget. 2017;8(13):21526-21538.

4. Enzinger PC, Mayer RJ. Esophageal cancer. N Engl J Med. 2003; 349(23):2241-2252.

5. He Z, Li G, Tang L, Li Y. SIX1 overexpression predicts poor prognosis and induces radioresistance through AKT signaling in esophageal squamous cell carcinoma. Onco Targets Ther. 2017;10:1071-1079.

6. Zheng S, Zhang X, Wang X, Li J. Downregulation of miR-138 predicts poor prognosis in patients with esophageal squamous cell carcinoma. Cancer Biomark. 2017;20(1):49-54.

7. Li L, Wang W, Zhang R, et al. High expression of LAMP2 predicts poor prognosis in patients with esophageal squamous cell carcinoma. Cancer Biomark. 2017;19(3):305-311.

8. Zhan XH, Jiao JW, Zhang HF, et al. A three-gene signature from protein-protein interaction network of LOXL2- and actin-related proteins for esophageal squamous cell carcinoma prognosis. Cancer Med. 2017;6(7):1707-1719.

9. Savitz AJ, Meyer DI. 180-kD ribosome receptor is essential for both ribosome binding and protein translocation. $J$ Cell Biol. 1993;120(4):853-863.
10. Tsai HY, Yang YF, Wu AT, et al. Endoplasmic reticulum ribosome-binding protein 1 (RRBP1) overexpression is frequently found in lung cancer patients and alleviates intracellular stress-induced apoptosis through the enhancement of GRP78. Oncogene. 2013;32(41):4921-4931.

11. Telikicherla D, Marimuthu A, Kashyap MK, et al. Overexpression of ribosome binding protein 1 (RRBP1) in breast cancer. Clin Proteomics. 2012;9(1):7.

12. Krasnov GS, Oparina N, Khankin SL, et al. [Colorectal cancer 2D-proteomics: identification of altered protein expression]. Mol Biol (Mosk). 2009;43(2):348-356. Russian.

13. Liang X, Sun S, Zhang X, et al. Expression of ribosome-binding protein 1 correlates with shorter survival in Her-2 positive breast cancer. Cancer Sci. 2015;106(6):740-746.

14. Pan Y, Cao F, Guo A, et al. Endoplasmic reticulum ribosome-binding protein 1, RRBP1, promotes progression of colorectal cancer and predicts an unfavourable prognosis. Br J Cancer. 2015;113(5):763-772.

15. Gao W, Li Q, Zhu R, Jin J. la autoantigen induces ribosome binding protein 1 (RRBP1) expression through internal ribosome entry site (IRES)-mediated translation during cellular stress condition. Int J Mol Sci. 2016;17(7).

16. Benyamini P, Webster P, Meyer DI. Knockdown of p180 eliminates the terminal differentiation of a secretory cell line. Mol Biol Cell. 2009;20(2):732-744.

17. Ogawa-Goto K, Tanaka K, Ueno T, et al. p180 is involved in the interaction between the endoplasmic reticulum and microtubules through a novel microtubule-binding and bundling domain. Mol Biol Cell. 2007;18(10): 3741-3751.

18. Barbe L, Lundberg E, Oksvold P, et al. Toward a confocal subcellular atlas of the human proteome. Mol Cell Proteomics. 2008;7(3):499-508.

19. Olsen JV, Blagoev B, Gnad F, et al. Global, in vivo, and site-specific phosphorylation dynamics in signaling networks. Cell. 006;127(3):635-648.

20. Cardoso CM, Groth-Pedersen L, Hoyer-Hansen M, et al. Depletion of kinesin 5B affects lysosomal distribution and stability and induces peri-nuclear accumulation of autophagosomes in cancer cells. PLoS One. 2009;4(2):e4424.

21. Diefenbach RJ, Diefenbach E, Douglas MW, Cunningham AL. The ribosome receptor, p180, interacts with kinesin heavy chain, KIF5B. Biochem Biophys Res Commun. 2004;319(3): 987-992.

22. Chirieac LR, Swisher SG, Ajani JA, et al. Posttherapy pathologic stage predicts survival in patients with esophageal carcinoma receiving preoperative chemoradiation. Cancer. 2005;103(7):1347-1355.

23. Chao YK, Chan SC, Liu YH, et al. Pretreatment T3-4 stage is an adverse prognostic factor in patients with esophageal squamous cell carcinoma who achieve pathological complete response following preoperative chemoradiotherapy. Ann Surg. 2009;249(3):392-396.

24. Huang J, Hu W, Pang L, Chen J, Yang H. Value of positive lymph node ratio for predicting postoperative distant metastasis and prognosis in esophageal squamous cell carcinoma. Oncol Res Treat. 2015;38(9):424-428.

25. Akita H, Doki Y, Yano M, et al. Effects of neoadjuvant chemotherapy on primary tumor and lymph node metastasis in esophageal squamous cell carcinoma: additive association with prognosis. Dis Esophagus. 2009;22(4):291-297.

26. Conio M, Gostout CJ. Histopathologic findings predicting lymph node metastasis and prognosis of patients with superficial esophageal carcinoma. Analysis of 240 surgically resected tumors. Gastrointest Endosc. 2001;54(5):668-669.

27. Yu X, Zhang J, Zhong H, et al. Decreased tumor suppressor candidate 3 predicts poor prognosis of patients with esophageal squamous cell carcinoma. Int J Med Sci. 2016;13(12):963-969.

28. Liu Z, Yang T, Xu Z, Cao X. Upregulation of the long non-coding RNA BANCR correlates with tumor progression and poor prognosis in esophageal squamous cell carcinoma. Biomed Pharmacother. 2016;82:406-412. 
Cancer Management and Research

\section{Publish your work in this journal}

Cancer Management and Research is an international, peer-reviewed open access journal focusing on cancer research and the optimal use of preventative and integrated treatment interventions to achieve improved outcomes, enhanced survival and quality of life for the cancer patient.

The manuscript management system is completely online and includes

Submit your manuscript here: https://www.dovepress.com/cancer-management-and-research-journal

a very quick and fair peer-review system, which is all easy to use. Visit $\mathrm{http}: / / \mathrm{www}$.dovepress.com/testimonials.php to read real quotes from published authors. 